\title{
Digital Skills and Competencies in Schools
}

\author{
Sue Cranmer \\ Department of Educational Research, Lancaster University, UK \\ s.cranmer@lancaster.ac.uk
}

\begin{abstract}
This paper will compare a range of recently developed frameworks, which identify digital skills and competencies drawn from the United Kingdom (UK), from across the wider European Union, and internationally to include Australia. It will also briefly explore who and what is driving this agenda. The models will be set within the context of recent evidence that highlight the deficits that exist in children and young people's skills and competencies in order to emphasise the need for schools to address this issue. In order to consider the issue more practically, it will explore the digital skills and competencies of one young person who is currently in transition to explore how useful the frameworks are for the development of their skills. It will show the correspondence and divergence between the different frameworks and the composite headings which can be drawn from the content. Examples of these dimensions will be outlined to show how digital technologies, and particularly digital skills and competencies, can influence a specific transition from school to college.
\end{abstract}

Keywords: Digital skills, digital literacy, disability.

\section{Introduction}

A central problem of the digital technologies agenda is how to develop young people's skills and competencies to support immediate and longer-term life transitions. Learners need these skills and competencies to support their life transitions. Evidence about schools and what they are doing to develop digital skills is far from clear. There are different models of digital skills and competencies which have emerged in recent years in the United Kingdom (UK) and Europe [1, 2]. Whilst it is not immediately apparent who is driving this agenda, it includes in the UK, for example, the UK Government, and industry [3, 4, 5]. Likewise, this agenda is also being driven forward by government and industry in many other countries $[6,7,8]$.

This paper will compare a range of recently developed frameworks, which identify digital skills and competencies drawn from the UK, from across the wider European Union, and internationally to include Australia. It will also briefly explore who and what is driving this agenda. The models will be set within the context of recent evidence that highlight the deficits that exist in children and young people's skills and competencies in order to emphasise the need for schools to address this issue. In order to consider the issue more practically, it will consider the digital skills and 
competencies of one young person who is currently in transition to explore how useful the frameworks are for the development of their skills. These data are drawn from a small pilot project currently underway, exploring how young people in mainstream schools who are blind or visually impaired use digital technologies - such as the computer and Internet - for learning at school, home and in other environments. In particular, this paper will draw on the data to address the following research questions:

- How far do the frameworks enable understanding of young people's digital skills and competencies?

- How might the frameworks be implemented in practice?

- How do digital technologies support life transitions?

\section{Background}

'Digital skills and competencies' as a term describes an often expanded multifaceted range of competencies which are difficult to define given the different perspectives and professional disciplines engaged in the field [9]. These skills have variously been called 'digital literacy', 'media literacy', 'computer skills' and 'Internet literacy'.

Debates about what should constitute digital skills and competencies are prolific and the abundance of these debates - also set out in policy - in themselves contest Prensky's notion of 'digital natives' [10]. Prensky argued that 'digital natives', young people born in the last 3 decades who have always been surrounded by digital media: are '...all "native speakers" of the digital language of computers, video games and the Internet' (p.1). As so-called 'digital immigrants', Prensky argued that (older) educators needed to up-skill in order to address new ways of learning in order to engage this new type of learner. Since 2001, much research has contested the view that all young people have an innate capacity to learn how to use digital technologies effectively. A recent face-to-face survey was carried out in the UK by the Princes Trust to explore what they refer to as 'digital literacy' [11]. The survey included 1,378 young people aged between 15 to 25 years of age which also comprised 265 young people classed as NEET (Not in Education, Employment or Training). Whilst the survey found that many young people feel confident in carrying out a wide range of tasks, particularly social activities such as e-mailing friends $(66 \%)$, accessing social media sites (64\%), 12\% reported that they do not think their computer skills are good enough to use in the job they want; $10 \%$ of NEETS feel "out of their depth" using a computer; and $17 \%$ of NEETS believe they would be in work today if they had better computer skills. A larger project, 'EU Kids Online' again carried out a face-to-face survey, in this case with 25,0009 to 16 -year-olds in 25 European countries to understand their online activities, skills and self-efficacy. The data show that children from lower socio-economic status homes are gaining less digital skills and competencies than their more affluent counterparts; younger children in general have less developed skills accompanied by less confidence using them; girls have slightly less confidence about their skills than boys; and the majority of children gauged their skills to be less than their parents (only 36\% said it is "very true that they know more than their parents'). As the authors reported, this finding again debunks the myth of 
the digital native [12]. These findings could be expanded upon drawing on other international research studies which demonstrate evidence about the level of development of children's digital skills and competencies and whether they are underdeveloped and in turn require intervention in order to address this.

In recognition that a problem does exist, there have been numerous calls and initiatives for the development of young people's digital skills and competencies in schools including from industry in the UK. The Confederation for British Industry has highlighted the need for action in this respect [4], as have the video games and video effects industries [5]. The UK government have recently issued a new curriculum to be introduced in September 2014 for England for both primary (ages 5 to 11 years) and secondary (ages 11 to 16 years) children and young people. Within the curriculum for computing, it is stated that: 'Computing also ensures that pupils become digitally literate - able to use, and express themselves and develop their ideas through, information and communication technology - at a level suitable for the future workplace and as active participants in a digital world' [3, p.204]). More broadly, the European Commission's Europe 2020 flagship initiative Digital Agenda for Europe emphasises the need for young people, workers and all citizens to have '... the skills needed to meet 21 st century challenges' [6]. These attributes are seen as important for economic recovery and growth within the European Union. In Australia, the Melbourne Declaration on the Educational Goals for Young Australians [7] states that in a digital age, young people need to be highly skilled: 'Rapid and continuing advances in information and communication technologies (ICT) are changing the ways people share, use, develop and process information and technology. In this digital age, young people need to be highly skilled in the use of ICT. While schools already employ these technologies in learning, there is a need to increase their effectiveness significantly over the next decade (p.5).'

\section{Introduction of Frameworks for Digital Skills and Competencies}

In light of the developments summarised above, three frameworks for the development of digital skills and competencies have been identified for analysis in this paper. Criteria for inclusion were:

- Must be based on empirical research.

- Must be recent (i.e. developed in the last 5 years).

- Must be broken down into different elements and descriptions of the constituent skills and competencies.

- Must be written in the English language.

- Must be represented in a diagrammatic form for ease of top-level representation.

- Must have the main focus on digital skills and competencies rather than broader elements of 21 st-century skills.

In light of these criteria, frameworks from Australia, Europe and the United Kingdom were selected for comparison: two aimed at helping teachers to develop their students' skills [2, 13]; the other aimed at supporting the development of "All citizens" to "create consensus at European level about the components of Digital 


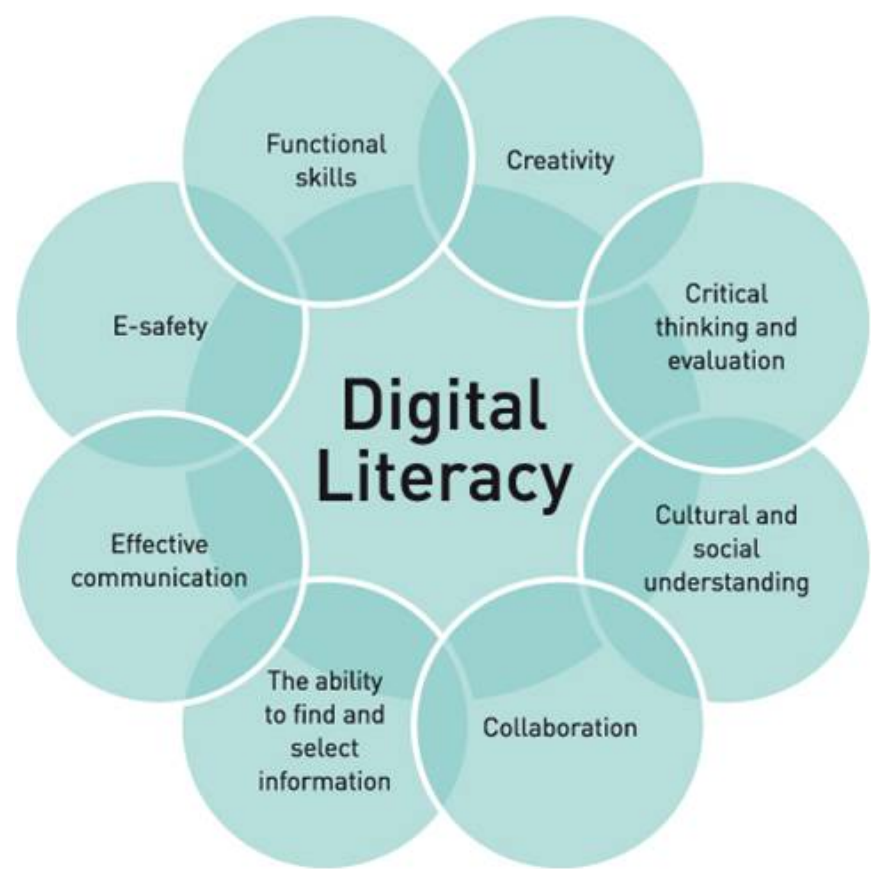

Fig. 1. Futurelab [2]

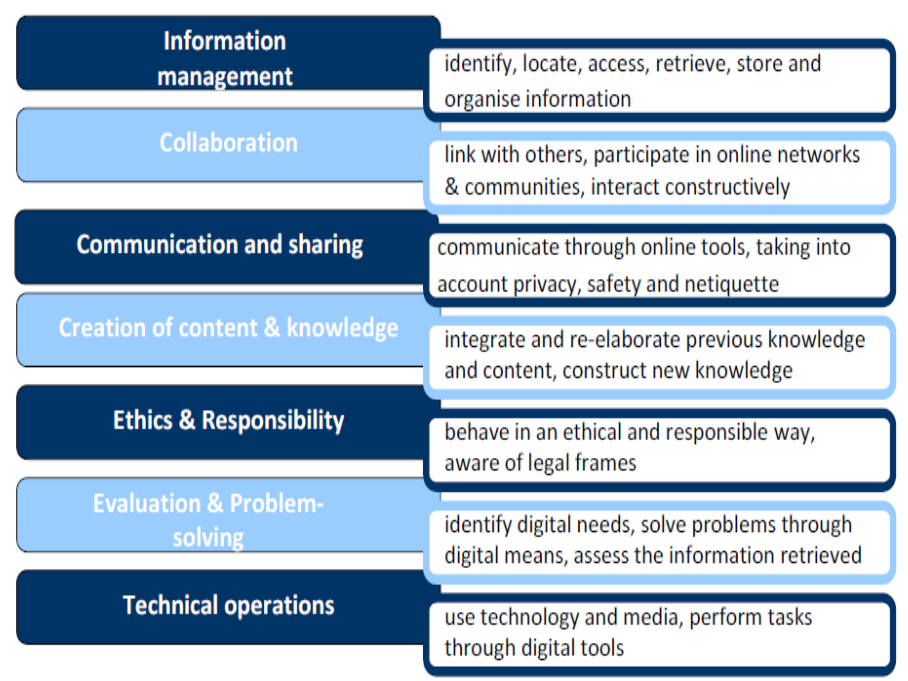

Fig. 2. Institute for Prospective Technological Studies [1]

Competence" [14, p.7]. Given the large number of models of digital skills and competencies developed, the selection could be expanded upon in a further extended study (see for instance the National Council for Teachers of English in the United 


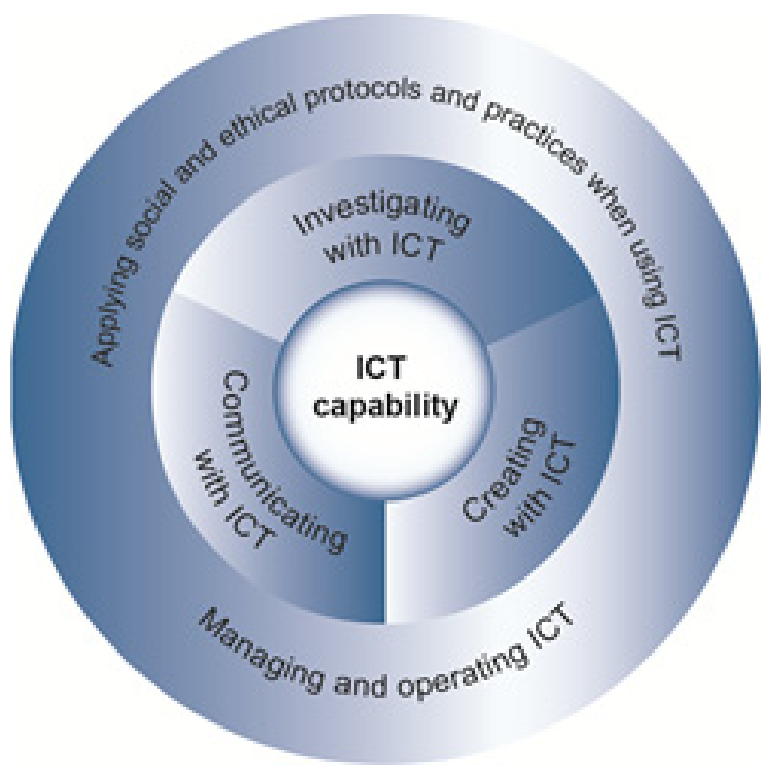

Fig. 3. The Australian Curriculum, Assessment and Reporting Authority [19]

States [15] or BECTA [16] in the UK. The details considered in each of these frameworks were: components of the framework (see Figures 1, 2 and 3); which organisation produced it; when it was produced; who it was aimed at; what its stated purpose was; and how it was produced.

\section{Methodology and Methods}

In order to consider the frameworks more practically, an individual case has been drawn from an ongoing small-scale study about how young people with visual impairments in mainstream schools use digital technologies for learning. Firstly, the three frameworks were considered straightforwardly by placing them side-by-side to compare and contrast the differences and correspondences. The comparison took place at the level of headings and brief description of content which represent each dimension of digital skills and competencies, as set out in Table 1.

Table 1. The elements of each framework included in the analysis

\begin{tabular}{lrlllr}
\hline Framework 1: Futurelab & Framework 2: IPTS & Framework 3: ACARA \\
\hline Diagram p.19; & Diagram p.5; outline & Diagram p.5; outline \\
descriptions and ideas for & description of different & description of different \\
how teachers can foster & dimensions of digital & dimensions of digital \\
digital competencies for & competencies pp.5-6 & competencies pp.5-6 \\
learners pp.22-45 & & & & \\
\hline
\end{tabular}


The decision was made to explore the frameworks at this level of detail for the purposes of cross comparison. However it should be noted that the IPTS framework in particular sets out the different dimensions of digital competencies in much more detail, and analysis of this could be usefully expanded in further work. Also, the IPTS and ACARA self/student assessment frameworks could be used to evaluate young people's digital skills and competencies in depth.

Data from the individual case being researched as part of the ongoing digital technologies for learning by visually impaired young people project was then drawn upon to look more practically at the different frameworks. The case was selected from the larger project sample as an example of a student who is currently in transition from school to college, to understand more concretely how the selected frameworks appear in terms of understanding and potentially developing young people's digital skills and competencies. This approach therefore provides a means of exploring the frameworks more practically and how they might be implemented in practice. In relation to this student's visual impairment and therefore the relevance of the case to understanding the development of digital skills and competencies, Passey argues that there are differences between learners which need to be recognised so that learning can accommodate '... learner's individual needs, their interests and aptitudes, so they can gain to the greatest possible level' [17, p.103].

The ongoing small-scale study from which this data are drawn is exploring the situation for visually impaired young people in terms of access to digital technologies, uses and how digital technologies influence learning in both formal and out-of-school settings. It is also considering how digital skills and competencies developed by this group of visually impaired young people support formal and out-of-school learning and it is this part of the project which is drawn on here. The research is qualitative in design; and involves 16 participants between the ages of 11 to 18 years. School visits include a semi-structured interview with each young person, observation in the classroom of how they use digital technologies for learning and interviews with the support team. Sixteen detailed case studies will be developed from the data. Where possible, common themes will be drawn out across the sample through adopting a constant comparison approach [18]. Nevertheless, this may not be appropriate because the young people in the sample may have other impairments, which may vary across the group and weaken a cross comparison approach.

'Laura' (a pseudonym) is a 16-year-old girl with a significant visual impairment who lives in the North of England. She was interviewed in May 2014 shortly before taking her examinations and before leaving school in July 2014. She has been selected for this paper as she is currently in transition and making choices about whether to move into the sixth form at the school or outside to a different college. Indeed, during a semi-structured interview she reflected on how her digital skills and competencies could influence her future career. She was also observed in a science lesson using digital technologies. Nevertheless, as this was a revision class, she was mainly using an iPad to access a Microsoft (MS) PowerPoint presentation prepared by her teacher through using the iPad's zoom facility during which the whole class including Laura were being asked questions. This engagement with technology was more limited than if Laura had been, for instance, using the iPad to create content, communicating and collaborating. 


\section{Comparison of Frameworks}

\subsection{Dimensions/Headings}

Comparison of the three frameworks showed that for the most part, the categories described and the dimensions of each framework can be mapped onto each other (see Table 2). This is perhaps unsurprising given that when considered in detail, it emerged that all 3 were underpinned by international research and analysis of other models. Even so, these similarities also represent a convergence to a large degree of what are seen to be the digital skills and competencies needed by young people today in Australia, Europe and within a specific European Union country, the UK. Where headings do exist which are not reflected in other frameworks, the content within these headings has mainly been conflated under other headings. For instance, the Futurelab framework has a separate category for collaboration. Nevertheless, elements of collaboration have been integrated into the IPTS and ACARA dimensions under the heading of communication.

The order of the headings in Table 2 has been dictated by the dimensions/headings set out in the Futurelab framework (starting from Functional skills on the upper left of the diagram) and then the other frameworks are set out by how they correspond to this. Nevertheless, the diagrammatic form of the Futurelab framework suggests less of a hierarchy than the other two frameworks which have a linear order which could potentially be viewed as a hierarchy of their relative importance. The extent of intentionality for this is unclear.

Given the overall similarities and convergence between the frameworks, it was decided to form composite headings by looking across the headings from the 3 original frameworks to show correspondence. This also allows for consideration of how the dimensions of the frameworks can be used practically to interpret one young person's skills. The paper does not intend to evaluate the usefulness of each framework individually given the extent to which they overlap; however, it will briefly consider how the content described by three of the dimensions/headings may concur or differ across the frameworks.

\section{Practical Application of the Frameworks}

Table 2 has shown how the content of the dimensions/headings within each framework map onto each other. This section will therefore focus on the practical application of the digital skills and competencies as represented by the composite headings. Three dimensions have been chosen given that this is a short paper, and being selective will allow for more depth in exploration of the issues. Nevertheless, this could be usefully expanded upon. The three dimensions selected have also been chosen where data from the case study of Laura can provide examples of content within each category. 
Table 2. The dimensions/headings within the frameworks that map onto each other taking account of the content

\begin{tabular}{|c|c|c|c|}
\hline & $\begin{array}{l}\text { Framework 1: } \\
\text { Futurelab }\end{array}$ & $\begin{array}{l}\text { Framework 2: } \\
\text { IPTS }\end{array}$ & $\begin{array}{l}\text { Framework 3: } \\
\text { ACARA }\end{array}$ \\
\hline \multirow[t]{8}{*}{ Dimensions/headings } & Functional skills & Problem solving & $\begin{array}{l}\text { Managing and } \\
\text { operating ICT }\end{array}$ \\
\hline & Creativity & Content creation & Creating with ICT \\
\hline & $\begin{array}{l}\text { Critical thinking } \\
\text { and } \\
\text { evaluation }\end{array}$ & $\begin{array}{l}\text { Information } \\
\text { (described as } \\
\text { Information } \\
\text { management in } \\
\text { the diagram) }\end{array}$ & Investigating with ICT \\
\hline & $\begin{array}{l}\text { Cultural and } \\
\text { social } \\
\text { understanding }\end{array}$ & $\begin{array}{l}\text { Does not directly } \\
\text { map. Elements of } \\
\text { the Communication } \\
\text { dimension are } \\
\text { closest to this. }\end{array}$ & $\begin{array}{l}\text { Does not directly map. } \\
\text { Elements of the } \\
\text { Applying social and } \\
\text { ethical protocols and } \\
\text { practices dimension } \\
\text { are closest to this. }\end{array}$ \\
\hline & Collaboration & $\begin{array}{l}\text { Integrated into } \\
\text { Communication }\end{array}$ & $\begin{array}{l}\text { Integrated into } \\
\text { Communication }\end{array}$ \\
\hline & $\begin{array}{l}\text { The ability to } \\
\text { find and select } \\
\text { information }\end{array}$ & $\begin{array}{l}\text { Information } \\
\text { (described as } \\
\text { Information } \\
\text { management within } \\
\text { the diagram) }\end{array}$ & Investigating with ICT \\
\hline & $\begin{array}{l}\text { Effective } \\
\text { communication }\end{array}$ & Communication & $\begin{array}{l}\text { Communicating with } \\
\text { ICT }\end{array}$ \\
\hline & E-safety & Safety & $\begin{array}{l}\text { Applying social and } \\
\text { ethical protocols and } \\
\text { practices when using } \\
\text { ICT }\end{array}$ \\
\hline
\end{tabular}

\subsection{Functional Skills/Managing and Operating ICT/Problem Solving}

All 3 frameworks have aspects of this dimension which mainly describes having the appropriate technical knowledge and skills needed to carry out the other dimensions of the frameworks. The IPTS framework is interesting in that it includes that users also need to be able to identify digital competence gaps within this dimension. This is described as: 'To understand where own competence needs to be improved or 
updated, to support others in the development of their digital competence, to keep upto-date with new developments' (p.6). This is an important dimension of the frameworks in emphasising the need to update and develop further technical knowledge and skills.

This dimension is useful for understanding the functional skills which Laura possesses alongside somewhat more extended skills to use digital technologies to overcome visual impairment. She is a competent user of an iPad which she accesses through the built-in accessibility functions. She also uses a laptop with supernova magnification as an assistive technology. She has the functional skills to access a range of devices and software to support her studies. In relation to the need to update and expand knowledge and skills, it is interesting that Laura says that she is able to do most of the things she wants to with digital technologies. Nevertheless, this does not account for other applications and potential uses which Laura might find helpful but does not yet know exist.

\subsection{Creativity/Content Creation/Creating with ICT}

All 3 frameworks describe creativity as being an essential competence online both in terms of content creation and in having the necessary digital skills and competencies to be actively creative more broadly. For example, in the Futurelab framework, creativity is described in terms of: creating a product or output; thinking creatively and imaginatively; and creating knowledge and knowledge production. The IPTS framework also includes the need to consider copyright and licenses within this dimension, and programming, which the others do not.

In relation to Laura, this category has particular resonance as she said that her favourite subject at school is 'Creative media'. For this subject, she needs to create both films and photographs. She described how she really enjoys going out filming, editing the results in Adobe Premiere Pro and using an optical mouse which enlarges what she is editing in detail. Her interest in the subject combined with having the digital skills and competencies to do this means that her decision about what to do next - whether school or college - hangs on this subject and where best to pursue it. She is as yet undecided. But her ability to do well in this subject (enabled by digital skills and competencies), and to have the skills needed to do so, are crucial in this decision.

\subsection{E-Safety/Safety/Applying Social and Ethical Protocols and Practices When Using ICT}

There is more divergence between the 3 frameworks in this dimension, immediately signalled by the broader ACARA heading. Nevertheless, all 3 frameworks include the issue of personal safety. The Futurelab model for E-safety puts the onus on critical thinking and what is referred to as 'critical awareness', protecting yourself online personally and in terms of copyright, knowing the risks, cyberbullying; and virus protection. The IPTS dimension is somewhat similar, emphasising safety and security, physical and psychological well-being, risks and threats, protection of personal data, 
and cyberbullying. It also includes protection of the environment. The ACARA dimension of 'Applying social and ethical protocols and practices when using ICT' is broader and appears to place more prominence on intellectual property rights, storage, digital information security practices; and personal security. It also takes a wider view in the expectation of a developed understanding on the impact of ICT on society and on the benefits and consequences of ICT, setting this dimension within a wider context.

When Laura was asked about online safety, interestingly her immediate response was in relation to having been bullied off-line rather than online. She said that this had happened more at primary school than at the secondary school which she attends now. And she put this down to being the only person with a disability. She said that she had been called 'horrible' names. In relation to transition, she said: '... It just makes you tougher, it makes you in some ways ready for the workplace because it's not going to be all happy and all sweet and everyone is going to be okay with everything'. More positively, Laura said that she had not been bullied much online. On Facebook she only accepts people who she knows face-to-face and who she would like to see her 'timeline'. Also on Facebook if somebody acted in a way that upset her, she said that she could 'block them' suggesting she felt more empowered to do this online than off.

Whilst the issue here for Laura is off-line rather than online bullying, it is included here to show how she feels more empowered online to prevent being bullied compared with being off-line. It is also interesting that she has turned being bullied off-line to positive effect, as in some way being prepared for the workplace. Obviously it is of concern that she anticipates that she may be bullied when she enters the workplace possibly due to her visual impairment. Nevertheless, the way she rationalises how she has been bullied in the past suggests she has a well-developed coping strategy for this.

\subsection{How Could Frameworks Be Implemented?}

One of the questions that this paper set out to answer was how far the frameworks can be implemented in schools, taking account of the more practical consideration of a specific young person's skills and competencies at the point of transition from school to college or sixth form. The straightforward answer for all students would be to carry out student evaluations as in the ACARA framework, or ask students to self-evaluate as in the IPTS framework, and then to design interventions to address any areas needing further development. Nevertheless, the curriculum in many countries is already tightly packed and this may prevent initiatives designed to develop young people's digital skills and competencies gaining resonance. In the new curriculum for England, for example, it will be important to gauge how far digital skills and competencies will be developed through their stipulation within the curriculum for computing; and how far they can also be embedded across other subjects in the curriculum. In Australia, it will be useful to monitor the impact following the introduction of the ACARA standard. In this, further research will be necessary. 


\subsection{Skills and Competencies in Specific Life Transitions}

A key question for this paper is also how do digital technologies support life transitions? In the case of this paper the question is more one of how do underpinning digital skills and competencies support life transitions. In relation to Laura, there is one clear example where the subject of 'creative media' is influencing Laura's choice of college or sixth form as it is a subject she would really like to continue with. It is also a subject in which the part played by digital technologies, and digital skills and competencies, are fundamental. It would be very useful to relate the findings of this chapter more broadly to studies of transition and particularly research about children and young people's 'resilience' which is known to be important for successful transition [19]. Resilience factors are seen to support transition so that children and young people are able to exhibit '.. positive adaptation in circumstances where one might expect, due to atypical levels of stress, a significant degradation in coping skills to take place' (p.1). Indeed, in relation to digital skills, Graham has conceptualised this as 'techno-resiliency to describe the characteristics and strategies through which individuals are able to cope with challenging technology-related circumstances [20]. Further work is needed to understand how digital technologies and the underpinning skills and competencies needed to use them can support transition. This would seem to be highly relevant in the debate about how digital competencies and skills are needed both to equip young people for changes in their lives as well as in order to be able to adopt newer technologies.

\section{Conclusions}

This paper has compared a range of recently developed frameworks and shown how the dimensions contained within them often converge. It has also sketched out previous studies which highlight the deficits that exist in some children and young people's skills and competencies. The current study could usefully be further expanded through looking in detail at a much larger sample of frameworks and explore these in relation to a larger sample of young people in transition. In an extended study, it would also be useful to set the frameworks within their cultural context in terms of why particular dimensions and elements of each framework have been given the emphasis they have. For example, Futurelab's E-safety description appears to draw heavily on current concerns in the UK about children's online safety and the risk of online grooming and sexual predation, and exposure to pornography, rather than for instance, the ACARA framework which places more emphasis on intellectual property and the wider consequences of ICT on society. It would be useful to understand the trends and concerns within each country which may be traceable into the frameworks themselves. It is also clear that the frameworks alone do not ensure implementation, and given that in Australia and the UK, for instance, emphasis on the development of these skills appears to be growing in terms of further inclusion in curricula, further research would be helpful to understand how these developments work in practice. 
Acknowledgements. The author would like to thank the tutors and young people who kindly participated in the study about how young people with visual impairments in mainstream schools use digital technologies for learning. Also, to thank Professor Don Passey for generously sharing ideas and giving much support in developing this paper and other projects.

\section{References}

1. Ferrari, A.: Digital Competence in Practice: An Analysis of Frameworks. Institute for Prospective Technological Studies, Seville (2012), http://ftp.jrc.es/EURdoc/ JRC68116.pdf (retrieved August 30, 2014)

2. Hague, C., Payton, S.: Digital literacy across the curriculum. Futurelab, Bristol (2010), http: / /www2 futurelab.org.uk/resources / documents / handbooks / d igital_literacy.pdf (retrieved August 30, 2014)

3. Department for Education (DfE): The national curriculum in England. Framework document. Reference: DFE-00177-2013 (2013), http: / /www.gov.uk/dfe/ nationalcurriculum (retrieved August 30, 2014)

4. Confederation for British Industry: First steps: A new approach for our schools - ambition (noun) a desire and determination to achieve success. CBI, London (2012), http: // www.cbi.org.uk/media/1845483/cbi_education_report_191112.pdf (retrieved August 30, 2014)

5. Livingstone, I., Hope, A.: Next Gen. Transforming the UK into the world's leading talent hub for the video games and visual effects industries: A Review. Nesta, London (2011), http: / /www. nesta.org.uk/ library/documents / NextGenv32.pdf (retrieved August 30, 2014)

6. European Commission: Europe 2020 Strategy (2010), http://ec.europa.eu/ europe2020/index_en.htm (retrieved August 30, 2014)

7. Ministerial Council on Education, Employment, Training \& Youth Affairs (MCEETYA): The Melbourne Declaration on the Educational Goals For Young Australians (2008), http: / /www. curriculum. edu.au/verve/resources/National_Declar ation_on_the_Educational_Goals_for_Young_Australians.pdf (retrieved August 30, 2014)

8. Partnership for 21st Century Skills (P21): Framework for 21st Century Learning, http: / /www.p21.org/about-us/p21-framework (retrieved August 30, 2014)

9. Meyers, E.M., Erickson, I., Small, R.V.: Digital literacy and informal learning environments: an introduction. Learning, Media and Technology 38(4), 355-367 (2014)

10. Prensky, M.: Digital natives, digital immigrants. On the Horizon 9(5), 1-6 (2001)

11. Princes Trust: Digital Literacy Survey (2013), http://www.princes-trust. org.uk/pdf/DIGITAL_LITERACY_2013B.pdf (retrieved August 30, 2014)

12. Sonck, N., Livingstone, S., Kuiper, E., de Haan, J.: Digital literacy and safety skills. EU Kids Online, London School of Economics \& Political Science, London (2011), http: / / eprints. 1se.ac.uk/33733/1/Digital\%201iteracy 20 and\%2 0 safetyo20skills\%201sero.pdf (retrieved August 30, 2014)

13. Australian Curriculum Assessment and Reporting Authority (ACARA): Information and communication technology (ICT) capability, http://australiancurriculum. edu. au (retrieved August 30, 2014) 
14. Ferrari, A.: DIGICOMP: A Framework for Developing and Understanding Digital Competence in Europe. Institute for Prospective Technological Studies, Seville, Spain (2013), http://ftp.jrc.es/EURdoc/JRC83167.pdf (retrieved August 30, 2014)

15. National Council of Teachers of English: 21st-Century Literacies. A policy research brief. National Council of Teachers of English, Urbana, IL (2007), http://www. ncte. org/library/NCTEfiles/Resources/Magazine/Chron110721CentLitB rief.pdf (retrieved August 30, 2014)

16. BECTA: Digital literacy. Teaching critical thinking for our digital world. BECTA, Coventry (2010), http: / / inyurl . com/k5rgdru(retrieved August 30, 2014)

17. Passey, D.: Inclusive technology enhanced learning: Overcoming Cognitive, Physical, Emotional and Geographic Challenges. Routledge, New York (2014)

18. Strauss, A.: Qualitative analysis for social scientists. Cambridge University Press, Cambridge (1987)

19. Newman, T., Blackburn, S.: Interchange 78. Transitions in the Lives of Children and Young People: Resilience Factors. Scottish Executive Education Department, Edinburgh (2002), http: / / www. scotland.gov.uk/Resource/Doc / 46997/0024005.pdf (retrieved August 30, 2014)

20. Graham, R.G.: Techno-resiliency: An Exploration of Professional Practices in the Field of Technology-Enriched Teaching and Learning. Lancaster University, Lancaster, Unpublished $\mathrm{PhD}$ Thesis (2014) 